\title{
Aposentadorias e Distribuição da Renda no Brasil: uma nota sobre o período 1981 a 2001
}

\author{
Carlos Roberto Ferreira*
}

Sumário: 1. Introdução; 2. Revisão Bibliográfica; 3. Material e Método; 4. Resultados; 5. Conclusão.

Esse estudo avalia a contribuição das aposentadorias e pensões para a desigualdade da distribuição do rendimento domiciliar per capita no Brasil, através da técnica de decomposição do índice de Gini. Concluiu-se que o rendimento das aposentadorias e pensões contribuem para aumentar a desigualdade da distribuição da renda no Brasil.

This study evaluates the contribution of the retirements and pensions for the inequality of the per capita domiciliay income distribution in Brazil, through the technique of decomposition of Gini's index. The conclusion drawn is that the retirement and pension income contributes to the increase of inequality of the income distribution in Brazil.

Palavras-chave: previdência social; aposentadorias e pensões; desigualdade.

Códigos JEL: D31; D63

\section{INTRODUÇÃO}

Na segunda metade da década de 90 , intensificaram-se os debates sobre a Previdência social brasileira, em conseqüência dos seus significativos e crescentes resultados deficitários. As mudanças no mercado de trabalho, na estrutura demográfica, na Constituição aprovada em 1988 e distorções do sistema previdenciário, têm colaborado para aumentar o déficit previdenciário, diminuir o valor dos beneficios, aumentar impostos e criar privilégios para poucos beneficiários.

A soma de gastos com aposentadorias dos servidores da união, estados e municípios e setor privado, de acordo com Gastos (2002) corresponde a 9\% do Produto Interno Bruto (PIB), enquanto a média dos países ricos, representados pela Organização para a Cooperação do Desenvolvimento Econômico (OCDE), é de $7,4 \%$ do PIB.

Distorções no valor de aposentadorias e pensões, privilegiando minorias que recebem a maior parte da renda dos benefícios, em detrimento de uma grande maioria, evidencia a existência de problemas no

* Professor do Departamento de Economia da Universidade Estadual de Londrina - UEL. Rua Jorge Velho, 529 Apt.74 Londrina Pr. CEP 86010.600 e-mail: robert@uel. br 
modelo de repartição simples, no qual, princípios previdenciários como solidariedade e redistribuição não estão sendo observados. Isso fica evidente pela falta de uniformidade de critérios e requisitos nos Regimes de Previdência ${ }^{1}$ Social brasileira, criando-se regimes especiais, o que propicia a chamada redistribuição invertida de renda, de forma que os que ganham menos financiam os que aposentam mais cedo e que recebem mais.

Diante desse quadro, o objetivo central deste trabalho é avaliar a contribuição das aposentadorias e pensões para a desigualdade da distribuição do rendimento domiciliar per capita no Brasil, no período de 1981 a 2001.

\section{REVISÃO BIBLIOGRÁFICA}

O maior problema estrutural brasileiro é a desigualdade da distribuição da renda persistente. O país já passou por diversas fases de crescimento e de crises e não conseguiu combater a desigualdade.

De acordo com o Instituto de Pesquisa Econômica Aplicada, Instituto de Pesqiusa Econômica Aplicada (1996), o Brasil, apresenta um dos maiores graus de desigualdade do mundo. Segundo esse relatório, a renda média dos $10 \%$ mais ricos é quase trinta vezes maior do que a renda média dos $40 \%$ mais pobres. Comparativamente, na Holanda a renda média dos $10 \%$ mais ricos é quatro vezes maior do que a renda dos $40 \%$ mais pobres.

De acordo com Instituto de Pesqiusa Econômica Aplicada (1996), o efeito distributivo dos gastos sociais é il desfavorável mesmo aos contingentes mais pobres da população. Esse trabalho mostra que estimativas do Banco Mundial, referentes a 1990 indicam que o valor per capita dos gastos sociais, sem incluir os benefícios pagos pela previdência, relativos aos $20 \%$ mais pobres da população, era $13 \%$ inferior à cifra correspondente aos $80 \%$ restantes da população. Esse diferencial aumenta quando se consideram os benefícios pagos pela previdência. $O$ valor per capita dos gastos sociais referentes aos $20 \%$ mais pobres era $40 \%$ menor do que o valor relativo aos outros $80 \%$ da população. Esses dados mostram que, quando se consideram os benefícios pagos pela previdência, o perfil da distribuição é ainda mais desfavorável aos segmentos mais pobres.

De acordo com Stephanes (1999) em países onde os princípios básicos do sistema previdenciário são respeitados, o modelo de repartição simples funciona com as contribuições dos atuais trabalhadores, por um período de 35 a 40 anos, financiando as aposentadorias dos inativos, que, em média, recebem o benefício por 18 anos, enquanto as próximas gerações irão financiar os benefícios dos que estão contribuindo. De acordo com o mesmo autor, existem casos de empresas estatais brasileiras terem idade média de concessão de aposentadorias com 48 anos; isso numa classe de pessoas que têm uma expectativa de vida em torno de 80 anos, o que equivale dizer que embora tenham contribuído menos de 30 anos, em média, essas pessoas vão gozar uma aposentadoria durante 32 anos. Se levar em conta que esse benefício gera uma pensão por mais oito anos, a média final sobe para 40 anos.

Outra restrição ao modelo de repartição simples é a redistribuição invertida de renda. Os mais ricos têm o poder de influenciar decisões favoráveis às suas categorias, aposentando-se com menos idade, enquanto os trabalhadores com menos renda aposentam-se com mais idade. A base de cálculo do valor dos benefícios, que tem sido usada, são as remunerações dos últimos anos de vida profissional. Nesse caso, os que ganham melhores salários são mais favorecidos porque, em regra, atingiram essa posição ao final de suas carreiras ou estão prestes a se aposentar, enquanto aqueles que ganham menos, e em geral realizam tarefas que empregam mais força física, e conseqüentemente, têm declínio de renda nos últimos anos de carreira.

A falta de equilíbrio entre os regimes previdenciários é apontado como um dos principais problemas estruturais, que afeta negativamente a previdência. De acordo com Medici (1998) em 1997, 17\%

\footnotetext{
${ }^{1} \mathrm{O}$ sistema brasileiro é composto de três conjuntos de regimes. No setor privado tem-se o Regime Geral de Previdência Social, administrado pelo Instituto Nacional do Seguro Social (INSS) e os Regimes Complementares. No setor público tem-se os Regimes dos Servidores Públicos (União,Estados, Municípios e poderes Executivo, Legislativo e Judiciário).
} 
dos beneficiários da previdência faziam parte do Regime dos Servidores Públicos e consumiram 53\% dos gastos com aposentadorias e pensões, enquanto que os outros $83 \%$ eram provenientes do RGPS e receberam 47\% dos gastos com aposentadorias e pensões. Em 2001, de acordo com Lahóz (2003), o déficit da previdência chegou a 61,5 bilhões de reais, sendo que 48,6 bilhões ou aproximadamente $79 \%$ do déficit foram referentes a gastos com servidores públicos e 12,8 bilhões (21\%) foram de gastos com o regime geral do INSS.

Esses números podem ser melhor entendidos, quando verifica-se os valores médios pagos de aposentadorias e pensões aos dois regimes previdenciários. No INSS, o valor médio do beneficio rural é de um salário mínimo e o médio urbano de 2,1 salários mínimos por mês. Muitos dos benefícios dos servidores do poder legislativo e do poder judiciário são baseados em condições que propiciam alcançar, por exemplo, o valor médio de 36,2 salários mínimos por mês. Ressalta-se, porém, que $80 \%$ dos servidores públicos brasileiros aposentam com rendimentos de até R\$ 1,2 mil (Stephanes (1999)).

Outro problema é o acúmulo de remunerações. É comum o servidor civil ou militar, aposentar-se no serviço público por tempo de serviço, ingressar-se no regime INSS e obter aposentadoria por idade. Se o servidor civil exercia atividade concomitante, coberta pelo mesmo regime, ou por outro, também pode receber outra aposentadoria, por tempo de serviço, ou por idade.

Observa-se através desses poucos exemplos, que o sistema previdenciário no Brasil apresenta privilégios e distorções pela falta de uniformidade de critérios e requisitos dos regimes de previdência, fugindo dos conceitos e fundamentos básicos que compõem a doutrina do sistema previdenciário, contribuindo para aumentar as diferenças no valor dos beneficios dos trabalhadores.

Tais problemas foram ganhando maior importância à medida que alguns fatores como: mudanças demográficas, composição do mercado de trabalho e a aprovação da Constituição de 1988 contribuíram para a impossibilidade de sustentação do sistema de Previdência Social no Brasil.

Demograficamente, a população mundial e em especial, a brasileira, tem apresentado baixas taxas de fecundidade, aumento da longevidade e urbanização acelerada. Essa interação tem levado a um maior crescimento da população idosa em relação aos demais grupos. A pesquisa de Camarano (2002) mostra que a participação da população maior de 60 anos na população brasileira mais do que dobrou no último meio século, passando de 4\% em 1940 para 8\% em 1996. A autora estima que em 2001, a população brasileira com mais de 60 anos seria da ordem de 15 milhões de habitantes, e que, em 2020, aproximadamente $15 \%$ da população será composta por idosos.

Esse cenário é visto pelos estudiosos do assunto com preocupação, por demandar mudanças no perfil das políticas públicas, colocando novos desafios para o Estado, a sociedade e a família. A transferência de recursos na sociedade é um deles. Por exemplo, as demandas de saúde, implicando em maior rnações hospitalares, consultas ambulatoriais, remédio etc., aumento da demanda sobre o sistema previdenciário, através de aposentadorias e pensões, adicionando-se ainda que o envelhecimento requer também cuidados e atenção especial da família.

De acordo com Stephanes (1999), os impactos da dinâmica demográfica com respeito à Previdência Social refletem-se tanto nas despesas com beneficios quanto no lado das receitas. Para manter o equilíbrio no sistema de repartição simples, o elemento fundamental, considerando-se somente as variáveis demográficas, é a estrutura etária da população em cada momento, pois é ela que define a relação entre beneficiários e contribuintes.

As pirâmides populacionais brasileira mostram significativas modificações na estrutura etária, com o progressivo incremento da população com mais de 60 anos. De acordo com as projeções de Cechin (2002), observa-se o estreitamento gradual da base da pirâmide demográfica e o alargamento do seu topo entre 1980 e 2001, refletindo os efeitos da queda da proporção da população jovem em relação ao total e o aumento gradativo da população com idade avançada.

A sustentabilidade da Previdência Social exige novas reformas que levem em conta essa tendência de vidas mais longas. Dessa forma, ajustes como o alongamento do período de trabalho e de contribuição são necessários, criando novos estímulos para que a aposentadoria ocorra em idades mais altas. 
Com relação a composição do mercado formal, nos últimos anos o seu comportamento tem sido de queda. De acordo com Najberg e Ikeda (1999), observa-se uma tendência de redução da participação de salários no total de produção, especialmente no setor industrial, no qual tal participação é mais expressiva no mercado formal. O setor industrial tem perdido posição em favor do setor de comércio e de serviços, que emprega cada vez mais trabalhadores, mas com elevado grau de informalização. Além disso, constata-se uma tendência de remunerar o trabalhador formal com menor salário fixo e com participação nos lucros através de gratificação, bônus ou dividendos, sem que haja incidência de contribuição tanto do empregado quanto do empregador. Essas novas tendências contribuem bastante para diminuir a arrecadação da Previdência Social.

Segundo Stephanes (1999), a relação de contribuintes ativos por era de oito, enquanto para as décadas de 1970 e 1980 essa relação foi de 4,2 e 3,2 respectivamente. De acordo com dados de Ornélas (2002), essa mesma relação caiu de 2,4 em 1991 para 1,7 em 1997. Essa queda implicou em sucessivos aumentos das alíquotas de contribuição, redução no valor real dos benefícios e utilização de receita de impostos para cobrir o déficit da previdência. Na União Européia, de acordo com Ornélas e Vieira (2002), existem em média quatro trabalhadores para cada aposentado, em 2040 serão apenas dois trabalhadores por aposentado e na Alemanha, por exemplo, esta relação estará próxima de um para um em 2040.

Ornélas e Vieira (2002) destacam que a base de contribuintes da previdência no Brasil esteve sempre abaixo do seu potencial. Em 1997, cerca de 62\% da população ocupada não contribuía para o Regime Geral de Previdência Social (RGPS) e 56\% dela não contribuía para nenhum tipo de previdência. 0 alto grau de emprego informal, as tecnologias poupadoras de mão-de-obra e a crescente taxa de evasão das contribuições sociais no mercado formal fazem reduzir sensivelmente as fontes de recursos dos benefícios. Esses dados mostram a importância do mercado informal no país e a necessidade de uma revisão na estrutura tributária e na legislação trabalhista, de maneira que aumentem os incentivos para a sua regularização.

Com a aprovação da Constituição de 1988 aumentou expressivamente a quantidade de benefícios e o seu valor médio, principalmente para os benefícios rurais, que passaram de meio para um salário mínimo. De acordo com Delgado e Cardoso (2002), a previdência rural pagou, em 1998, 6,91 milhões de aposentadorias, pensões, rendas mensais vitalícias e amparos previdenciários aos seus segurados. Conforme Brandt (2001), entre 1988 e 2000, o número de benefícios pagos pelo sistema aumentou $71,6 \%$, passando de 11,6 milhões em 1988 para 19,9 milhões em 2000. O aumento da quantidade e do valor médio dos benefícios fez com que a despesa com benefícios pagos pela previdência mais do que duplicasse, passando de 2,6\% do PIB em 1988 para 6,1\% em 2000. De Acordo com Stephanes (1999), se não houver nenhuma reforma, a projeção de evolução da despesa com benefícios, em percentual do PIB, será de aproximadamente 8\% do PIB em 2014 e 10\% do PIB em 2025.

As mudanças na Constituição de 1988 referentes à Previdência Social representaram grande conquista social. $O$ problema na concessão de beneficios sem a exigência de contribuição suficiente para cobrir os gastos. O resultado foi o crescimento das despesas e a elevação do déficit previdenciário.

Dessa forma, a reforma ou o ajuste do sistema previdenciário fez-se ais destacam-se: a elevação do déficit previdenciário, a concessão de de previdência e a introdução de conceitos e fundamentos básicos que compõem a doutrina universal, reestruturando-a para o futuro.

No entanto, sabe-se que é extremamente difícil implementar um sistema de previdência com regras universais e compatíveis com os reações dos segmentos protegidos, que se utilizarão de todos os meios para manter a que se encontram.

Mas, a partir da década de 1990, com projeções que apontavam regimes de previdência no Brasil, a sua reforma tornou-se inevitável. Com a estabilidade monetária, tornando as contas públicas transparentes, pôde-se perceber com clareza os problemas do sistema previdenciário.

Frente a um quadro desfavorável, o governo propôs algumas medidas que visassem à redução das distorções existentes no sistema previdenciário, procurando também buscar o equilíbrio de suas contas. 
Após quatro anos de discussões aprovou-se a Emenda Constitucional embro de $1998^{2}$. Para Stephanes (1999) e Brandt (2001), a Emenda Constitucional que modifica o sistema de Previdência Social representou um avanço, embora aquém das necessidades de ajuste dos regimes de previdência, e prevêem que dentro de mais alguns anos ela terá que ser revista.

De maneira geral, a reforma aprovada tem muita ênfase fiscal, sob a alegação de que a manutenção do sistema até então vigente, altamente deficitário e responsável pela elevação do déficit público, poderia acabar comprometendo a estabilidade de preços e diminuir o nível de atividade econômica, devido ao impacto sobre a taxa de juros. Com respeito ao caráter distributivo do sistema até então vigente, pouco foi revisto, e a tendência é continuar reproduzindo a distribuição de renda vigente no país, ou seja, continuou-se a concentrar os benefícios nos segmentos que o mercado já privilegia. Observa-se que muitos dos princípios básicos da doutrina previdenciária continuam não contribuir para a redução da desigualdade da distribuição da renda no Brasil.

Assim, os segmentos da população que formam a força de trabalho e estão inseridos em um contexto de informalidade de vínculos empregatícios, ou ocupam postos de trabalho de baixa qualidade, com elevada rotatividade e pouca ascensão profissional, estão excluídos do sistema ou obtêm um valor de beneficio previdenciário muito baixo.

\section{MATERIAL E MÉTODO}

O presente estudo tem por base as informações coletadas nas Pesquisas Nacionais por Amostra de Domicílios (PNAD), no período tem periodicidade anual desde 1971, sendo interrompida por ocasião dos Censos Demográficos (1970, 1980, 1991 e se de um levantamento anual realizado por meio de uma amostra dos domicílios que abrange todo o país, exceto a área rural ados da antiga região Norte (Acre, Amapá, Amazonas, Pará, Rondônia e Roraima). Para as pesquisas da década de 90, essa abrangência geográfica foi mantida, ou seja, a PNAD continuou a cobrir todo o país, com exceção da área rural dessas seis unidades da federação.

Ressalta-se também, que, para as PNADs de 1992 a 1996 foram utilizados nsão corrigidos com base na contagem populacional e divulgados juntamente com os microdados da PNAD de 1997.

O procedimento metodológico adotado pelo IBGE implica que cada pessoa da resenta um determinado número de pessoas da população. Os dados individuais são fornecidos com o peso ou xpansão de cada indivíduo. Isso permite que os cálculos sejam elaborados ponderando-se cada observação pelo respectivo peso. Todos os cálculos, neste trabalho, foram feitos considerando o peso ou fator de expansão de cada domicílio da amostra da PNAD, fornecido pelo IBGE.

Foram analisados apenas os domicílios particulares permanentes com do rendimento domiciliar. Domicílios com rendimentos não declarados foram excluídos da análise.

As informações das PNADs são de boa qualidade, mas é preciso observar algumas características da natureza desses dados, as quais são restrições que precisam ser levadas em consideração na análise dos resultados, conforme alerta Hoffmann (2002b).

De acordo com as notas metodológicas do IBGE (2001), "considerou-se como rendimento mensal domiciliar a soma dos rendimentos mensais dos moradores do domicílio, exclusive os das pessoas cuja condição no domicílio fosse pensionista, empregado doméstico ou parente do empregado doméstico".

Para se obter o rendimento domiciliar per capita, dividiu-se o rendimento mensal do domicílio, excluindo pensionistas, empregados domésticos e seus parentes.

\footnotetext{
${ }^{2}$ Disponível no site http://www.previdenciasocial.gov.br
} 


\subsection{Metodologia}

Neste trabalho utilizou-se algumas medidas de desigualdades, como o índice de Gini $(G)$, e o índice $T$ e $L$ de Theil. ${ }^{3}$ Neste trabalho utiliza-se também outras medidas de desigualdade ${ }^{4}$, tal como a porcentagem da renda em poder dos $50 \%$ mais pobres $\left(50^{-}\right)$, dos $10 \%$ mais ricos $\left(10^{+}\right)$, dos $5 \%$ mais ricos $\left(5^{+}\right)$, ou dos $1 \%$ mais ricos $\left(1^{+}\right)$. Esses índices são medidas associadas diretamente à posição de um único ponto da curva de Lorenz, ou seja, às separatrizes (decis e percentis) da distribuição do rendimento.

\subsubsection{Decomposição do índice de Gini}

Na decomposição do índice de Gini a literatura de Pyatt et alii (1980) mostra como o índice de Gini pode ser decomposto quando se considera a divisão do rendimento analisado em vários componentes.

Seja $z_{i}$ o rendimento da $i$-ésima pessoa. Neste trabalho considera-se o rendimento domiciliar per capita, considerando que ele é o resultado da soma de $k$ parcelas:

$$
z_{i}=\sum_{h=1}^{k} z_{h i}
$$

Vamos admitir que os rendimentos $z_{i}$ estão ordenados de maneira que $z_{1} \leqslant z_{2} \leqslant \ldots \leqslant z_{n}$, sendo $n$ o tamanho da população. Então $i$ é a posição de ordem do rendimento $z_{i}$.

Pode-se verificar que o índice de Gini $(\mathrm{G})$ da distribuição de $z_{i}$ é

$$
G=\frac{2}{n \mu} \operatorname{cov}\left(z_{i}, i\right)
$$

onde $\mu$ é a média dos $z_{i}$.

Pyatt et alii (1980) definem a razão de concentração do componente $z_{h i}$ como

$$
C_{h}=\frac{2}{n \mu_{h}} \operatorname{cov}\left(z_{h i}, i\right)
$$

onde $\mu_{h}$ é a média dos $z_{h i}$.

A participação do $h$-ésimo componente no rendimento total é

$$
\phi_{h}=\frac{\mu_{h}}{\mu}
$$

Pode-se deduzir que

$$
G=\sum_{h=1}^{k} \phi_{h} C_{h}
$$

Vamos indicar por $i_{h}$ os números de ordem associados aos valores de $z_{h i}$ se eles fossem colocados em ordem crescente. Os $i_{h}$, da mesma maneira que $i$, variam de 1 a $n$. Note-se, entretanto, que para determinando $z_{h i}$, o respectivo valor de $i$ (o número de ordem do correspondente $z_{i}$ ) não vai, em geral, coincidir com $i_{h}$ (a posição desse $z_{h i}$ na ordenação dos valores desse componente). Analogamente a (2), o índice de Gini de $z_{h i}$ é

$$
G_{h}=\frac{2}{n \mu_{h}} \operatorname{cov}\left(z_{h i}, i_{h}\right)
$$

De (3) e (6) obtem-se

$$
R_{h}=\frac{C_{h}}{G_{h}}=\frac{\operatorname{cov}\left(z_{h i}, i\right)}{\operatorname{cov}\left(z_{h i}, i_{h}\right)}
$$

\footnotetext{
3 Tais medidas de desigualdade podem ser encontradas detalhadamente em Hoffmann (1998).

${ }^{4}$ Ressalta-se que essas medidas não atendem ao princípio de Pigou-Dalton.
} 
Pyatt et alii (1980) denominaram $R_{h}$ de "razão de correlação de ordem", ressaltando que não é um coeficiente de correlação de ordem. Eles mostram que

$$
R_{h} \leqslant 1
$$

De (5) e (7) segue-se que

$$
G=\sum_{h=1}^{k} \phi_{h} R_{h} G_{h}
$$

Essa expressão mostra como o índice de Gini de $z_{i}$ está associado com os índices de Gini de cada componente.

\section{RESULTADOS}

A seguir apresentam-se os resultados obtidos para as medidas de desigualdade de renda e a decomposição do índice de Gini para o Brasil, de 1981 a 2001.

\subsection{Desigualdade do rendimento domiciliar per capita no Brasil: 1981 a 2001}

Os resultados apresentados refletem a situação do conjunto das pessoas que formam os domicílios brasileiros quanto ao aspecto da distribuição dos seus rendimentos.

Vale lembrar que, para se calcular o $L$ de Theil é necessário excluir os domicílios com rendimento declarado igual a zero, porque esse índice tende a infinito quando a renda de um domicílio tende a zero. Dessa forma, apresenta-se na Tabela 1 uma coluna contendo a porcentagem de domicílios que foram desconsiderados para esse cálculo por terem rendimento igual a zero. Cabe ressaltar que todos os demais indicadores de desigualdade foram calculados incluindo os domicílios com rendimento igual a zero.

A Tabela 1 mostra a evolução da desigualdade do rendimento domiciliar per capita obtidos através do cálculo do índice de Gini, T de Theil e L de Theil. Observa-se que a desigualdade manteve-se elevada durante todo o período analisado. Nota-se o sistemático crescimento da desigualdade após o Plano Cruzado em 1986, o valor excepcionalmente baixo em 1992 e novamente um crescimento, mantendo-se relativamente ríodo 1993-1997. Ocorre uma pequena diminuição da desigualdade entre 1998 e 1999. Observa-se na Tabela 1 que, excetuando 1981, 1984, 1986 e 1992, as medidas de desigualdade em 1999 são menores do que em qualquer outro ano do período analisado. Em 2001, observa-se que a desigualdade voltou a ter um pequeno crescimento.

As pessoas que se encontram entre os $10 \%$ mais ricos se apropriam de aproximadamente $48 \%$ do total da renda, enquanto os $50 \%$ mais pobres detêm cerca de $12 \%$ da renda, conforme pode-se ver na Tabela 1. A razão entre a renda total dos 10\% mais ricos e a renda total dos $50 \%$ mais pobres em 2001 foi de 3,7 , ou seja, as pessoas que compõem os $10 \%$ mais ricos detém uma renda 3,7 vezes maior do que toda a renda dos $50 \%$ mais pobres.

Esta estabilidade da desigualdade tem atravessado os mais variados ciclos institucionais, políticos e econômicos da história recente do país. Observa-se que os $50 \%$ mais pobres perceberam entre $10,7 \%$ e $13,2 \%$ da renda, enquanto os $10 \%$ mais ricos perceberam entre $45,6 \%$ e $53 \%$ da renda total.

No período analisado, as pessoas que se encontram entre os $5 \%$ mais ricos se apropriam de aproximadamente $34,5 \%$ do total da renda e os $1 \%$ mais ricos ficam com $14,2 \%$ do total. Em 2001 , a razão entre a renda total dos $5 \%$ mais ricos e a renda total dos $50 \%$ mais pobres foi de 2,7 e entre a renda total dos $1 \%$ mais ricos e a renda total dos $40 \%$ mais pobres foi de 1,7 .

Verifica-se que o percentual de renda recebido pelos mais pobres nos últimos sete anos é praticamente o mesmo, e que o percentual recebido pelos mais ricos também apresentou comportamento semelhante. Observa-se que, em matéria de distribuição de renda, o país apresenta uma indesejável estabilidade. 
Tabela 1 - Distribuição do rendimento domiciliar per capita, no Brasil, de 1981 a 2001: Índice de Gini $(G)$, T de Theil $(T)$, L de Theil $(L)$, percentual de domicílios com rendimento igual a zero, percentagem da renda correspondente aos $50 \%$ mais pobres (50-) e aos $10 \%$ mais ricos (10+)

\begin{tabular}{|c|c|c|c|c|c|c|}
\hline Anos & $G^{(1)}$ & $T^{(1)}$ & $L^{(2)}$ & $\begin{array}{c}\text { \% rendi- } \\
\text { mento } \\
\text { igual a zero }\end{array}$ & $50-{ }^{(1)}$ & $10+{ }^{(1)}$ \\
\hline 1981 & 0,582 & 0,675 & 0,625 & 0,65 & 13,2 & 46,2 \\
\hline 1983 & 0,594 & 0,712 & 0,644 & 0,93 & 12,6 & 47,1 \\
\hline 1984 & 0,587 & 0,695 & 0,630 & 0,47 & 13,7 & 47,0 \\
\hline 1985 & 0,595 & 0,718 & 0,659 & 0,41 & 12,6 & 47,5 \\
\hline 1986 & 0,586 & 0,713 & 0,635 & 0,36 & 13,1 & 46,8 \\
\hline 1988 & 0,616 & 0,785 & 0,722 & 0,49 & 11,6 & 49,6 \\
\hline 1989 & 0,634 & 0,880 & 0,774 & 0,49 & 10,7 & 51,2 \\
\hline 1990 & 0,612 & 0,766 & 0,711 & 0,82 & 11,5 & 48,6 \\
\hline 1992 & 0,580 & 0,689 & 0,634 & 1,19 & 13,2 & 45,6 \\
\hline 1993 & 0,602 & 0,765 & 0,685 & 1,01 & 12,4 & 48,4 \\
\hline 1995 & 0,599 & 0,727 & 0,665 & 1,26 & 12,4 & 47,7 \\
\hline 1996 & 0,600 & 0,726 & 0,670 & 1,67 & 12,2 & 47,3 \\
\hline 1997 & 0,600 & 0,731 & 0,673 & 1,38 & 12,2 & 47,5 \\
\hline 1998 & 0,598 & 0,728 & 0,662 & 1,31 & 12,4 & 47,6 \\
\hline 1999 & 0,592 & 0,706 & 0,645 & 1,25 & 12,8 & 47,1 \\
\hline 2001 & 0,594 & 0,720 & 0,650 & 1,56 & 12,7 & 47,2 \\
\hline
\end{tabular}

Fonte: IBGE-PNADs de 1981 a 2001; ${ }^{(1)}$ Calculado considerando todos os domicílios com declaração de rendimento; (2) Considerando apenas domicílios com rendimento positivo.

\subsection{Decomposição do índice de Gini}

Com a utilização da metodologia de decomposição do índice de Gini conforme parcelas do rendimento domiciliar per capita, pode-se observar a participação de cada componente na formação do Gini global, para cada ano analisado. Especial atenção é dada ao rendimento das aposentadorias e pensões, objeto de estudo neste trabalho.

A Tabela 2 mostra a decomposição do valor médio (VM) e a participação percentual [(\%) $\left.\phi_{k}\right]$ dos componentes do rendimento domiciliar per capita.

Observa-se que os rendimentos do trabalho principal contribuem com a maior parcela no total dos rendimentos, embora tenha diminuído sua participação a partir de 1989. Em 1981, o rendimento do trabalho principal correspondia a $82,7 \%$ do rendimento domiciliar total. Em 1990, a participação dessa parcela na renda total passa a ser $81,7 \%$, chegando, em 2001 , a uma participação de $74,7 \%$ no rendimento domiciliar total. No período analisado, em média, a sua participação no total foi de $79,9 \%$.

As aposentadorias e pensões contribuem com a segunda maior parcela no total dos rendimentos. Esse componente, ao longo do período analisado, aumentou a sua participação no valor do rendimento domiciliar per capita, principalmente a partir de 1989. Observa-se pela Tabela 2 que, entre os anos de 1981 a 1990, as aposentadorias e pensões contribuíram com aproximadamente 9,7\% do total de rendimentos, enquanto nos anos de 1992 a 2001 a sua participação aumentou para 15,5\%.

Em 1981, o rendimento de aposentadorias e pensões correspondia a 9,5\% do rendimento domiciliar total. Em 1992, a participação dessa parcela na renda total passa a ser de $14,2 \%$. Em 2001, a sua 
participação na renda total chegou a 18,6\%. A partir de 1992, observa-se que o crescimento da participação do valor das aposentadorias e pensões no rendimento domiciliar per capita tem sido cada vez mais acentuado, revelando a sua crescente importância para a renda domiciliar.

O componente juros, dividendos etc., no período de 1981 a 1993, participou com aproximadamente $2,4 \%$ do valor do rendimento domiciliar per capita. A partir de 1995, a sua participação caiu para menos de $1 \%$. Acredita-se que tal comportamento deve-se ao fim da correção monetária, com a implantação do Plano Real em 1994.

Os demais componentes do rendimento domiciliar per capita participaram no total dos rendimentos, em média, com 3,2\% para rendimento de outros trabalhos; 2,1\% para rendimento de aluguéis e $0,6 \%$ para rendimento de doações. Vale lembrar que os dados, para o componente do rendimento domiciliar per capita “doações", estão disponíveis a partir da PNAD de 1992.

Tabela 2 - Decomposição do valor médio (VM), em Reais ${ }^{1}$ de setembro de 2001, e a participação percentual $\left[(\%) \phi_{k}\right.$ ] dos componentes do rendimento domiciliar per capita. Brasil, de 1981 a 2001

\begin{tabular}{|c|c|c|c|c|c|c|c|c|c|c|c|c|c|c|}
\hline \multirow{3}{*}{ Ano } & \multicolumn{14}{|c|}{ Valor médio e sua participação percentual } \\
\hline & \multicolumn{2}{|c|}{$\begin{array}{l}\text { Trabalho } \\
\text { principal }\end{array}$} & \multicolumn{2}{|c|}{$\begin{array}{l}\text { Outros } \\
\text { trabalhos }\end{array}$} & \multicolumn{2}{|c|}{$\begin{array}{l}\text { Aposent. e } \\
\text { pensões }\end{array}$} & \multicolumn{2}{|c|}{ Aluguéis } & \multicolumn{2}{|c|}{ Doações } & \multicolumn{2}{|c|}{ Juros etc } & \multicolumn{2}{|l|}{ Total } \\
\hline & VM & $(\%) \phi_{k}$ & VM & $(\%) \phi_{k}$ & VM & $(\%) \phi_{k}$ & VM & $(\%) \phi_{k}$ & VM & $(\%) \phi_{k}$ & VM & $(\%) \phi_{k}$ & VM & $(\%) \phi_{k}$ \\
\hline 1981 & 170,67 & 82,7 & 5,41 & 2,6 & 19,69 & 9,5 & 5,95 & 2,9 & - & - & 4,66 & 2,3 & 206,38 & 100,0 \\
\hline 1983 & 149,12 & 81,5 & 5,88 & 3,2 & 18,78 & 10,3 & 4,68 & 2,6 & - & - & 4,53 & 2,4 & 182,99 & 100,0 \\
\hline 1984 & 148,61 & 81,5 & 5,77 & 3,2 & 18,74 & 10,3 & 4,18 & 2,3 & - & - & 5,05 & 2,7 & 182,35 & 100,0 \\
\hline 1985 & 179,88 & 82,2 & 6,91 & 3,2 & 22,23 & 10,2 & 4,06 & 1,8 & - & - & 5,63 & 2,6 & 218,70 & 100,0 \\
\hline 1986 & 256,52 & 83,7 & 10,08 & 3,3 & 26,99 & 8,8 & 6,85 & 2,2 & - & - & 6,03 & 2,0 & 306,47 & 100,0 \\
\hline 1988 & 191,02 & 84,3 & 7,23 & 3,2 & 18,39 & 8,1 & 4,58 & 2,0 & - & - & 5,42 & 2,4 & 226,64 & 100,0 \\
\hline 1989 & 233,25 & 82,4 & 9,88 & 3,5 & 27,70 & 9,8 & 6,82 & 2,3 & - & - & 5,58 & 2,0 & 283,23 & 100,0 \\
\hline 1990 & 190,58 & 81,7 & 8,44 & 3,6 & 24,94 & 10,7 & 5,53 & 2,4 & - & - & 3,76 & 1,6 & 233,25 & 100,0 \\
\hline 1992 & 167,47 & 79,0 & 6,18 & 2,9 & 29,94 & 14,2 & 2,83 & 1,3 & 0,86 & 0,4 & 4,66 & 2,2 & 211,94 & 100,0 \\
\hline 1993 & 180,03 & 78,3 & 7,59 & 3,3 & 32,46 & 14,1 & 2,62 & 1,1 & 1,02 & 0,4 & 6,34 & 2,8 & 230,05 & 100,0 \\
\hline 1995 & 238,03 & 78,5 & 10,68 & 3,5 & 43,18 & 14,2 & 6,83 & 2,3 & 1,75 & 0,6 & 2,67 & 0,9 & 303,12 & 100,0 \\
\hline 1996 & 240,15 & 78,3 & 10,54 & 3,4 & 44,61 & 14,5 & 7,26 & 2,4 & 1,56 & 0,5 & 2,73 & 0,9 & 306,84 & 100,0 \\
\hline 1997 & 239,33 & 78,2 & 9,97 & 3,3 & 46,67 & 15,2 & 6,60 & 2,2 & 1,75 & 0,6 & 1,87 & 0,5 & 306,19 & 100,0 \\
\hline 1998 & 235,45 & 76,2 & 9,83 & 3,2 & 51,67 & 16,7 & 7,42 & 2,4 & 2,13 & 0,7 & 2,68 & 0,8 & 309,19 & 100,0 \\
\hline 1999 & 192,44 & 75,5 & 7,58 & 3,0 & 45,43 & 17,8 & 5,55 & 2,2 & 1,78 & 0,7 & 2,10 & 0,8 & 254,91 & 100,0 \\
\hline 2001 & 222,31 & 74,7 & 9,57 & 3,2 & 55,18 & 18,6 & 5,74 & 1,9 & 2,00 & 0,7 & 2,72 & 0,9 & 297,52 & 100,0 \\
\hline Média & 202,18 & 79,9 & 8,22 & 3,2 & 32,29 & 12,7 & 5,47 & 2,1 & 1,60 & 0,6 & 4,15 & 1,7 & 253,74 & 100,0 \\
\hline
\end{tabular}

Fonte: IBGE-dados individuais das PNADs de 1981 a $2001 .{ }^{1}$ Utilizando como deflator o INPC-IBGE.

A Tabela 3 mostra a razão de concentração dos componentes do rendimento domiciliar per capita, $C\left(x_{k} \mid y\right)$, denotado na tabela como $C$. Sabe-se que um componente da renda contribui para aumentar a desigualdade quando a razão de concentração for maior que o índice de Gini. Os componentes do rendimento "outros trabalhos" e "aluguéis e juros" (com exceção dos anos de 1985 e 1986) tiveram razão de concentração maior do que o índice de Gini global, e contribuíram para aumentar a desigualdade medida pelo índice de Gini. Os componentes "trabalho principal" e "doações" tiveram razão de concentração menor do que o índice de Gini global, ou seja, em todo o período analisado, esses dois componentes contribuíram para reduzir a desigualdade medida pelo índice de Gini.

Para aposentadorias e pensões, a razão de concentração cresceu na primeira metade dos anos 80 , recuou em 1986, voltando a crescer a partir de 1988. Nos anos 90, a razão de concentração cresceu entre 
Tabela 3 - Razão de Concentração (C) na decomposição do índice de Gini do rendimento domiciliar per capita. Brasil, de 1981 a 2001

\begin{tabular}{|c|c|c|c|c|c|c|c|c|c|c|c|c|c|c|c|c|}
\hline \multirow{2}{*}{$\begin{array}{l}\text { Componente } \\
\text { do rendimento }\end{array}$} & \multicolumn{16}{|c|}{ Razão de concentração $(C)$ do rendimento } \\
\hline & 1981 & 1983 & 1984 & 1985 & 1986 & 1988 & 1989 & 1990 & 1992 & 1993 & 1995 & 1996 & 1997 & 1998 & 1999 & 2001 \\
\hline $\mathrm{TP}^{1}$ & 0,566 & 0,577 & 0,572 & 0,582 & 0,574 & 0,608 & 0,620 & 0,595 & 0,565 & 0,589 & 0,587 & 0,588 & 0,591 & 0,585 & 0,579 & 0,581 \\
\hline $\mathrm{OT}^{2}$ & 0,768 & 0,759 & 0,797 & 0,804 & 0,808 & 0,787 & 0,808 & 0,796 & 0,758 & 0,765 & 0,766 & 0,784 & 0,767 & 0,748 & 0,745 & 0,785 \\
\hline $\mathrm{AP}^{3}$ & 0,569 & 0,609 & 0,588 & 0,597 & 0,564 & 0,573 & 0,615 & 0,632 & 0,576 & 0,579 & 0,586 & 0,580 & 0,585 & 0,599 & 0,603 & 0,603 \\
\hline$A^{4}$ & 0,778 & 0,797 & 0,812 & 0,812 & 0,833 & 0,801 & 0,882 & 0,820 & 0,802 & 0,784 & 0,813 & 0,802 & 0,796 & 0,803 & 0,803 & 0,797 \\
\hline $\mathrm{D}^{5}$ & - & - & - & - & - & - & - & - & 0,368 & 0,423 & 0,399 & 0,436 & 0,380 & 0,413 & 0,354 & 0,395 \\
\hline $\mathrm{J}^{6}$ & 0,757 & 0,639 & 0,592 & 0,593 & 0,571 & 0,643 & 0,673 & 0,629 & 0,839 & 0,858 & 0,789 & 0,815 & 0,769 & 0,764 & 0,695 & 0,539 \\
\hline Gini total & 0,582 & 0,594 & 0,587 & 0,595 & 0,586 & 0,616 & 0,634 & 0,612 & 0,580 & 0,602 & 0,599 & 0,600 & 0,600 & 0,598 & 0,592 & 0,594 \\
\hline
\end{tabular}

Fonte: IBGE-dados individuais das PNADs de 1981 a $2001 ;{ }^{1}$ Trabalho Principal; ${ }^{2}$ Outros trabalhos; ${ }^{3}$ Aposentadorias e pensões; ${ }^{4}$ Aluguéis; ${ }^{5}$ Doações; ${ }^{6}$ Juros etc.

1992 e 1995, recuando um pouco em 1996 e voltando a crescer, acentuadamente, no final dos anos 90.

As aposentadorias e pensões apresentaram razão de concentração menor que o índice de Gini global em 9 dos 16 anos analisados. Para os anos de 1983, 1984, 1985, 1990, 1998, 1999 e 2001, a razão de concentração foi maior que o índice de Gini. Observa-se que, no final da década de 1990 e início do Século XXI, as aposentadorias e pensões deram uma contribuição maior para a desigualdade da distribuição do rendimento domiciliar per capita.

Observa-se que, em todo o período analisado, a razão de concentração para aposentadorias e pensões não apresentou recuos significativos. Pelo contrário, a tendência foi de crescimento. A razão de concentração para todos os componentes do rendimento domiciliar per capita foi positiva, mostrando que o valor de todos esses componentes tende a crescer com o rendimento domiciliar per capita.

Note-se que a razão de concentração de aposentadorias e pensões, ao longo do período analisado, é superior ou está ligeiramente abaixo da razão de concentração do rendimento do trabalho principal. O período de 1998 a 2001 apresenta razão de concentração de aposentadorias e pensões superior ao índice de Gini e, nos últimos dois anos, substancialmente maior do que a razão de concentração do rendimento de trabalho principal.

A Tabela 4 mostra a participação de cada componente para a formação do índice de Gini e a sua participação, em termos percentuais, para a formação do índice de Gini global.

Observa-se que o rendimento do trabalho principal é, em todo o período, o componente com a maior participação na formação do índice de Gini do rendimento domiciliar per capita, seguido pelo rendimento de aposentadorias e pensões.

Ao longo do período analisado, verifica-se que os rendimentos do trabalho principal, em média, representam $79,9 \%$ do rendimento total (Tabela 2) e originam a maior parcela do índice de Gini, participando com 78,1\% (Tabela 4).

Entre os demais componentes do rendimento, as aposentadorias e pensões vêm a seguir, representando, em média, $12,7 \%$ do rendimento total, originando a segunda maior parcela do índice de Gini, com 12,6\%. Em 1981, a contribuição dessa parcela para o índice de Gini foi de 9,3\%. Essa participação foi razoavelmente estável no período de 1981 a 1985, diminuiu de 1986 a 1988 e voltou a crescer a partir de 1989, quando contribuiu com 9,5\%. Em 1992, a contribuição dessa parcela para o índice de Gini total passa a ser de $14 \%$, acentuando esse crescimento na segunda metade dos anos 90 , principalmente nos anos de 1998 e 1999. A sua participação, cresce ainda mais em 2001, quando atinge $18,8 \%$ do índice de Gini, sendo esse o maior percentual de todo o período de 1981 a 2001. 
Entre 1992 e 2001, a parcela do índice de Gini do rendimento domiciliar principal, diminui 0,012, ao mesmo tempo que a parcela referente ao rendimento de aposentadorias e pensões aumenta 0,031.

Tabela 4 - Parcelas do índice de Gini $\left[\phi_{k} C\left(x_{k} \mid y\right)\right]$ (G) e o respectivo percentual, na formação do índice de Gini Global dos componentes do rendimento domiciliar per capita. Brasil, 1981 a 2001

\begin{tabular}{|c|c|c|c|c|c|c|c|c|c|c|c|c|c|c|}
\hline \multirow{3}{*}{ Ano } & \multicolumn{14}{|c|}{ Parcelas do índice de Gini $\left[\phi_{h} C\left(x_{k} \mid y\right)\right]$ (G) e as suas respectivas percentagens (\%) } \\
\hline & \multicolumn{2}{|c|}{$\begin{array}{l}\text { Trabalho } \\
\text { principal }\end{array}$} & \multicolumn{2}{|c|}{$\begin{array}{l}\text { Outros } \\
\text { trabalhos }\end{array}$} & \multicolumn{2}{|c|}{$\begin{array}{l}\text { Aposent. e } \\
\text { pensões }\end{array}$} & \multicolumn{2}{|c|}{ Aluguéis } & \multicolumn{2}{|c|}{ Doações } & \multicolumn{2}{|c|}{ Juros etc } & \multicolumn{2}{|l|}{ Total } \\
\hline & G & $\%$ & G & $\%$ & G & $\%$ & G & $\%$ & G & $\%$ & G & $\%$ & G & $\%$ \\
\hline 1981 & 0,468 & 80,4 & 0,020 & 3,5 & 0,054 & 9,3 & 0,023 & 3,9 & - & - & 0,017 & 2,9 & 0,582 & 100,0 \\
\hline 1983 & 0,471 & 79,3 & 0,024 & 4,1 & 0,063 & 10,5 & 0,020 & 3,4 & - & - & 0,016 & 2,7 & 0,594 & 100,0 \\
\hline 1984 & 0,467 & 79,4 & 0,025 & 4,3 & 0,060 & 10,3 & 0,019 & 3,2 & - & - & 0,016 & 2,8 & 0,587 & 100,0 \\
\hline 1985 & 0,479 & 80,5 & 0,025 & 4,2 & 0,061 & 10,3 & 0,015 & 2,5 & - & - & 0,015 & 2,5 & 0,595 & 100,0 \\
\hline 1986 & 0,480 & 81,9 & 0,026 & 4,5 & 0,050 & 8,5 & 0,019 & 3,2 & - & - & 0,011 & 1,9 & 0,586 & 100,0 \\
\hline 1988 & 0,512 & 83,3 & 0,025 & 4,1 & 0,047 & 7,6 & 0,016 & 2,6 & - & - & 0,015 & 2,4 & 0,616 & 100,0 \\
\hline 1989 & 0,511 & 80,6 & 0,028 & 4,4 & 0,060 & 9,5 & 0,021 & 3,3 & - & - & 0,014 & 2,2 & 0,634 & 100,0 \\
\hline 1990 & 0,486 & 79,4 & 0,029 & 4,7 & 0,068 & 11,0 & 0,019 & 3,2 & - & - & 0,010 & 1,2 & 0,612 & 100,0 \\
\hline 1992 & 0,446 & 76,9 & 0,022 & 3,8 & 0,081 & 14,0 & 0,011 & 1,9 & 0,002 & 0,3 & 0,018 & 3,1 & 0,580 & 100,0 \\
\hline 1993 & 0,461 & 76,5 & 0,025 & 4,2 & 0,082 & 13,6 & 0,009 & 1,5 & 0,002 & 0,3 & 0,023 & 3,9 & 0,602 & 100,0 \\
\hline 1995 & 0,461 & 77,0 & 0,027 & 4,5 & 0,084 & 14,0 & 0,018 & 3,0 & 0,002 & 0,4 & 0,007 & 1,1 & 0,599 & 100,0 \\
\hline 1996 & 0,461 & 76,8 & 0,027 & 4,5 & 0,084 & 14,0 & 0,019 & 3,2 & 0,002 & 0,3 & 0,007 & 1,2 & 0,600 & 100,0 \\
\hline 1997 & 0,462 & 77,0 & 0,025 & 4,2 & 0,089 & 14,8 & 0,017 & 2,8 & 0,002 & 0,4 & 0,005 & 0,8 & 0,600 & 100,0 \\
\hline 1998 & 0,446 & 74,5 & 0,024 & 4,0 & 0,100 & 16,7 & 0,019 & 3,2 & 0,003 & 0,5 & 0,006 & 1,1 & 0,598 & 100,0 \\
\hline 1999 & 0,437 & 73,7 & 0,022 & 3,7 & 0,107 & 18,2 & 0,018 & 3,0 & 0,002 & 0,4 & 0,006 & 1,0 & 0,592 & 100,0 \\
\hline 2001 & 0,434 & 73,0 & 0,025 & 4,3 & 0,112 & 18,8 & 0,015 & 2,6 & 0,003 & 0,4 & 0,005 & 0,8 & 0,594 & 100,0 \\
\hline Média & 0,468 & 78,1 & 0,025 & 4,2 & 0,075 & 12,6 & 0,017 & 2,9 & 0,002 & 0,4 & 0,012 & 2,0 & 0,598 & 100,0 \\
\hline
\end{tabular}

Fonte: IBGE-dados individuais das PNADs de 1981 a 2001.

Portanto, as aposentadorias e pensões contribuem significativamente na formação do índice de Gini em todo o período analisado, com clara tendência de crescimento na década de 90 .

$O$ índice de Gini total manteve-se alto durante todo o período analisado, comprovando que o rendimento domiciliar per capita é mal distribuído. O maior valor desse índice foi em 1989, atingindo 0,634 . Nos anos seguintes, o seu valor diminuiu, contrastando com o aumento da participação das aposentadorias e pensões na formação desse índice.

Para que se possa explicar a crescente contribuição das aposentadorias e pensões na desigualdade da distribuição do rendimento domiciliar per capita, a comparação com a parcela do rendimento de todos os trabalhos é bastante apropriada. A Tabela 5 mostra a evolução da desigualdade da distribuição da renda entre pessoas economicamente ativas (PEA) com algum rendimento e da distribuição do rendimento domiciliar per capita para o Brasil de 1981 a 2001.

A evolução da desigualdade da distribuição da renda entre pessoas economicamente ativas, medida através do índice de Gini, mostra valores relativamente baixos em 1981 e 1992, um grande crescimento em 1988 e 1989, um valor elevado em 1993, redução em 1995 e 1996, estabilidade entre 1996 e 1997, voltando a decrescer em 1998 e 1999.

Observa-se que, entre 1993 e 2001, o índice de Gini apresentou tendência de redução da desigualdade entre pessoas economicamente ativas com rendimento. Nesse período, o índice de Gini da PEA para o Brasil diminuiu 0,033. De acordo com Hoffmann (2002b), quando são consideradas todas as pessoas economicamente ativas com declaração de rendimento de todas as fontes, a redução da desigualdade é menor, mas não é desprezível. 
Tabela 5 - Índice de Gini para a distribuição do rendimento das pessoas economicamente ativas $\left(G_{P E A}\right)$ e para a distribuição do rendimento domiciliar per capita $\left(G_{R D P C}\right)$. Brasil, de 1981 a 2001

\begin{tabular}{|c|c|c|}
\hline ANO & $G_{P E A}^{(1)}$ & $G_{R D P C}$ \\
\hline 1981 & 0,572 & 0,582 \\
\hline 1983 & 0,591 & 0,594 \\
\hline 1984 & 0,586 & 0,587 \\
\hline 1985 & 0,599 & 0,595 \\
\hline 1986 & 0,589 & 0,586 \\
\hline 1988 & 0,617 & 0,616 \\
\hline 1989 & 0,636 & 0,634 \\
\hline 1990 & 0,607 & 0,612 \\
\hline 1992 & 0,574 & 0,580 \\
\hline 1993 & 0,604 & 0,602 \\
\hline 1995 & 0,589 & 0,599 \\
\hline 1996 & 0,585 & 0,600 \\
\hline 1997 & 0,585 & 0,600 \\
\hline 1998 & 0,581 & 0,598 \\
\hline 1999 & 0,572 & 0,592 \\
\hline 2001 & 0,571 & 0,594 \\
\hline
\end{tabular}

Fonte: $G_{P E A}$ - Hoffmann (2002a); $G_{R D P C}$ - IBGE-PNADs de 1981 a 2001; ${ }^{(1)}$ Estimativas obtidas a partir de tabela de distribuição de freqüência em 8 estratos.

A Tabela 5 mostra a evolução da medida de desigualdade da distribuição do rendimento domiciliar per capita ${ }^{5}$. Nesse período, o índice de Gini do rendimento domiciliar per capita para o Brasil diminuiu 0,008 . Constata-se que houve diminuição da desigualdade, mas essa diminuição é bem menos intensa do que no caso da distribuição do rendimento das pessoas economicamente ativas com rendimento, principalmente a partir de 1995.

Essa diferença de comportamento das duas distribuições pode ser explicado através da participação dos rendimentos de todos os trabalhos e da participação dos rendimentos das aposentadorias e pensões. A tabela 4 mostra que a participação dos rendimentos de todos os trabalhos, em 1993, foi de 0,486 e, em 2001, de 0,459, revelando que a participação desse componente diminuiu 0,027. Já a participação dos rendimentos das aposentadorias e pensões em 1993 foi de 0,082 e, em 2001, de 0,112, crescendo 0,030. O efeito compensatório nessas duas parcelas explica a relativa estabilidade do índice de Gini para o período.

A tendência de diminuição da participação dos rendimentos de todos os trabalhos no rendimento total é conseqüência da redução da participação dos salários no total da produção brasileira. Além disso, o mercado de trabalho formal tem constantemente apresentado quedas. Essas tendências contribuem bastante para diminuir a arrecadação da Previdência Social, conforme afirma Stephanes (1999).

O aumento da participação de renda das aposentadorias e pensões no rendimento total está associado ao crescente envelhecimento da população. Essa tendência é de crescimento, porque a população brasileira tem apresentado baixas taxas de fecundidade, aumento de longevidade e urbanização acelerada, levando a um maior crescimento da população idosa em relação aos demais grupos etários.

\footnotetext{
${ }^{5}$ A distribuição do rendimento das pessoas economicamente ativas é apropriada para analisar as mudanças mais diretamente associadas ao mercado de trabalho. Para analisar as diferenças de nível de renda, é mais apropriado considerar a classificação das pessoas de acordo com o rendimento domiciliarper capita.
} 
A combinação de mudanças na composição do mercado de trabalho, crescente informalização, flexibilização das relações trabalhistas, crescimento da população idosa, somados aos problemas existentes nos critérios e requisitos do sistema previdenciário, torna inviável o sistema vigente, devido ao constante crescimento do déficit previdenciário.

\section{CONCLUSÃO}

Os problemas da Previdência Social no Brasil são de longa data e, no decorrer dos anos, não houve a preocupação em solucioná-los, postergando ao máximo os ajustes necessários.

No caso da distribuição da renda, através dos dados das PNADs de i-se que o rendimento das aposentadorias e pensões tende a reproduzir a distribuição da renda no Brasil.

A decomposição do índice de Gini mostra que o rendimento de aposentadorias e pensões participou com a segunda maior parcela desse índice em todo o período analisado. Destaca-se que houve um nítido aumento dessa participação na década de 90.

A razão de concentração das aposentadorias e pensões, particularmente a partir de 1998, é maior do que o índice de Gini e superior à razão de concentração do rendimento do trabalho principal. Esses resultados mostram que os rendimentos de aposentadorias e pensões, administradas pelo governo federal, estão contribuindo para a aumentar a desigualdade da distribuição da renda no Brasil, mostrando que há necessidade de reforma no sistema previdenciário. É importante notar que um componente dos rendimentos que está diretamente sujeito a normas e leis, como as aposentadorias e pensões, esteja contribuindo para aumentar a desigualdade da distribuição de renda.

Os valores do índice de Gini da população economicamente ativa e do rendimento domiciliar per capita mostram a elevada desigualdade da distribuição da renda no Brasil. Observa-se que entre 1993 e 2001 houve uma redução da desigualdade da distribuição do rendimento das pessoas economicamente ativas. A redução da desigualdade no período torna-se quase desprezível quando é analisada a distribuição do rendimento domiciliar per capita. Esse fenômeno pode ser explicado, basicamente, pela crescente participação de aposentadorias e pensões na determinação da desigualdade.

Apesar da Reforma Constitucional $n^{\circ} 20$, o que se observou foram ajustes no Regime Geral de Previdência Social administrada pelo INSS, que atingem a grande maioria da população, enquanto a concessão de benefícios para o regime dos funcionários públicos permaneceu sem grandes modificações. A Emenda Constitucional teve como preocupação maior diminuir o déficit previdenciário. A distribuição dos benefícios de aposentadorias e pensões não foi modificada, e a tendência é a Previdência Social continuar a reproduzir a distribuição de renda vigente no país, concentrando a maior parte do valor dos benefícios nos segmentos mais ricos da sociedade.

É preciso buscar o aperfeiçoamento de critérios e requisitos dos regimes de previdência, adotando conceitos e fundamentos da doutrina do sistema de Previdência Social, com o objetivo de diminuir as diferenças no valor dos benefícios dos trabalhadores.

Apesar de a Previdência Social exercer papel fundamental na diminuição da pobreza no Brasil é saudável que as políticas públicas com caráter redistributivo sejam orientadas, principalmente, para os mais pobres, com o objetivo de diminuir a desigualdade na distribuição da renda.

Deve-se ter em vista, também, a arrecadação previdenciária do mercado de trabalho informal, cada vez mais presente no país. É necessário criar a possibilidade de contribuições menores, mesmo que isso resulte em benefício menor, mas seria, de todo modo, melhor do que manter um contingente enorme de trabalhadores à margem do sistema.

É necessário que os especialistas em Previdência Social encontrem soluções e criem regras adequadas para resolver o quadro igações. Também é preciso que o Congresso Nacional, responsável pela criação e aprovação de leis, aprove medidas corretas, aperfeiçoando a legislação e as políticas previdenciárias, embora isso seja dificultado pelas pressões de segmentos da sociedade que buscam manter privilégios. Sabe-se que esse é um tema politicamente delicado e que os prejuízos políticos-eleitorais 
aparecem de imediato, enquanto que os benefícios da reforma do sistema ocorrerão gradualmente ao longo do tempo. Mesmo assim, quando se verifica que não haverá possibilidades de sustentar o atual modelo previdenciário, tais desgastes são necessários, para que não se cometa uma enorme irresponsabilidade para com os idosos deste país.

\section{Referências Bibliográficas}

(2002). Gastos de rico para uma previdência pobre.

Brandt, R. (2001). Desenvolvimento social, previdência e pobreza no Brasil. Conjuntura Social, 12(2):7-63.

Camarano, A. A. (2002). Envelhecimento da população brasileira: uma contribuição demográfica. Technical Report 858, IPEA.

Cechin, J. (2002). A previdência social reavaliada-II. Conjuntura Social, 13(1):7-54.

Delgado, G. \& Cardoso, J. C. (2002). Universalização de direitos sociais mínimos no Brasil: o caso da previdência rural nos anos 90. http://www . previdênciasocial.gov.br/docs/volume03.pdf.

Hoffmann, R. (1998). Distribuição de renda: medidas de desigualdade e pobreza. Editora da Universidade de Sô Paulo.

Hoffmann, R. (2002a). Desigualdade e Pobreza no Brasil no período 1979-99. Technical report, Editora da Universidade de São Paulo. www . eco.unicamp.br/projetos/rurbano.html.

Hoffmann, R. (2002b). Desigualdade no Brasil: a contribuição das aposentadorias. Technical report, UNICAMP, Instituto de Economia. www .eco.unicamp.br/projetos/rurbano.html.

Instituto Brasileiro de Geografia e Estatística (2001). Pesquisa Nacional por Amostra de Domicílios. years 1981, 1983-86, 1988-89, 1990, 1992-93, 1995-99 e 2001.

Instituto de Pesqiusa Econômica Aplicada (1996). Relatório Sobre o Desenvolvimento Humano no Brasil.

Lahóz, A. (2003). É para ontem: por que a reforma da previdência é a principal tarefa do governo Lula em 2003. Revista Exame, pages 35-42.

Medici, A. C. (1998). Previdência social. Brasil em Números, 6:107-117.

Najberg, S. \& Ikeda, M. (1999). Previdência no Brasil: desafios e limites. In GIAMBIAGI, F. \& MOREIRA, M. M., editors, A economia brasileira nos anos 90, chapter 3, pages 261-290. BNDES, Rio de Janeiro.

Ornélas, W. (2002). O novo modelo previdenciário brasileiro: uma fase de transição. http: //www . previdenciasocial.gov.br/07\_08.htm.

Ornélas, W. \& Vieira, S. (2002). Novo Rumo para a Previdência Brasileira. http://www. previdenciasocial.gov.br/07\_09.htm.

Pyatt, G., Chen, C., \& Fei, J. (1980). The Distribution of Income by Factor Components. The Quarterly Journal of Economics, 95(3):451-473.

Stephanes, R. (1999). Reforma da previdência sem segredos. Record, Rio de Janeiro, 2 edition. 